\title{
Montessori Method and ICTs
}

\author{
http://dx.doi.org/10.3991/ijes.v4i1.5481 \\ Athanasios S. Drigas, and Eugenia G.Gkeka \\ NCSR DEMOKRITOS, Institute of Informatics and Telecommunications, Net Media Lab, Athens, Greece
}

\begin{abstract}
This article bridges the gap between the Montessori Method and Information and Communication Technologies (ICTs) in contemporary education. It reviews recent research works which recall the Montessori philosophy, principles and didactical tools applying to today's computers and supporting technologies in children's learning process. This article reviews how important the stimulation of human senses in the learning process is, as well as the development of Montessori materials using the body and the hand in particular, all according to the Montessori Method along with recent researches over ICTs. Montessori Method within information society age acquires new perspectives, new functionality and new efficacy.
\end{abstract}

Index Terms-didactical tools, educational games, ICTs, learning process, Montessori Method.

\section{INTRODUCTION}

In this article we analyze useful information technologies on Language, Mathematics, and Computer Science, various objects such as Geography, Ecology, Peace education, History and Artistic and Musical education. Especially, we are focused on how Montessori Method is applied in this education direction by the exploitation of ICT services and tools.

As Sabitzer reports, the recent development of scanning methods of human brain and its observation are related to pedagogy and didactics directly. In fact, according to neurodidactics, the new discipline, the complex function and mechanism of the knowledge establishes in the five senses (sight, sound, smell, taste, touch) and through elaboration and organization consolidates in long term memory. This complex learning process was encouraged by Maria Montessori (1870-1952) who created proper circumstances in the classroom, leading the pupil to become active: 'Help me to do it alone!' Nowadays, researcher proposes the implementation teamwork and projects so that the concern of students is stimulated through the use of ICTs. [1]

Shams and Seitz argue that through studies of learning multisensory training can be more effective than unisensory training plans. Once again it is confirmed that the multisensory brain needs to develop the acquisition of knowledge and the act of multisensory interactions and environments mainly during early development and at an individual level. Therefore, the authors make refer to Montessori who succeeded in multisensory educational methods used an amalgam of visual, auditory, tactile and kinesthetic approaches into educational protocols. In this way, the use of multimedia educational techniques facilitates multisensory learning. [2]

Zuckerman et al, offer a new classification of Manipulatives: "Montessori-inspired Manipulatives" (MiMs) and
"Froebel-inspired Manipulatives" (FiMs) [3]The term «manipulatives» is defined by the American Heritage ${ }^{\circledR}$ Dictionary of the English Language as: "any of various objects designed to be moved or arranged by hand as a means of developing motor skills or understanding abstractions, especially in mathematics". Zuckerman develops digital flow and system learning blocks, and as a researcher of tangible interfaces for learning and play, is inspired by Montessori traditional wooden objects created for 'Casa dei bambini', "Children's House" [4],[5] . Montessori's manipulatives concentrate on Cultural area, Language, Mathematics, and Sensorial. The concepts like texture, area, number, shape, color which are given by traditional manipulatives are enhanced by digital manipulatives to concepts such as the behavior of systems, feedback and control emergence, acceleration, social networks, communication, differential geometry [3], [5].

In addition to this, thinking through doing, performance, visibility, risk, and thick practice are five themes for interaction design. This paper [6] is referred to that active learning is facilitated by physical objects according to the Montessori Method and particularly by tangible manipulatives. Thus, thinking through doing, describes how mind and body produce learning and reasoning and also how physical action and especially the action and capability of the hand as it is the principle organ of expression.

Also, Zuckerman grades the learning Objects according to philosophical, epistemological, psychological design and he terms Montessori's category 'Conceptual Manipulation' category. He explains that Montessori materials are abstract concepts, e.g. he considers: "Montessori's 'long stairs' materials that are designed help children 'absorb' the concept of 'number'. The long stairs are large. The smallest one is $10 \mathrm{~cm}$ long, and the longest one is $100 \mathrm{~cm}$ long. They are painted red, to make them appealing to children". In his classification of classic objects under the Montessori Materials are included some toys in today's in toy stores and many materials in school setting seem to belong to the same grouping: Cuisenaire Rods, Shape Puzzles, Shape Sorting \& Stacking, Color Matching, Number Tiles, Alphabet Blocks. In classification of digital learning objects under Digital Conceptual Manipulation follow Neurosmith Music Blocks, Queensland Univ. Electronic Duplo Blocks, MIT's System Blocks MIT's Flow Blocks and Sussex Univ. Chromarium. [7]

"The hands which he employs for work are more intimately connected with his intelligence than any other parts of the body. They are the instruments of man's intelligence." as well as "the hand is the instrument of the mind"-MARIA MONTESSORI [8] 
PAPER

MONTESSORI METHOD AND ICTS

\section{LANGUAGE}

In the article [9] is evidenced that the combination of cooperative technologies and storytelling generates communication abilities, media literacy and subject understanding by individual storytelling and also inclusion by collective storytelling. This creation of multimedia digital story is supported by the 1001stories Toolkit -the 1001 stories authoring tool- which is provided to Italian schools by Politecnico di Milano for the PoliCultura contest. Also, the authors Di Blas et al., refer to the benefits of using physical Objects designed by Maria Montessori years before and the recent work of Zuckerman -MIT Media Lab's Digital MiMs- for enhancing the understanding of abstract concepts in young children as the sensorial approach to authoring of stories.

The approach "Cooperative Open Learning" as approach of progressive pedagogy in computer science and foreign languages is a teaching method based on Montessori and other supporter educationists. Thus, Sabitzer demonstrates two aspects of technology as a tool and as a subject in teaching and learning as well as some opinions and comments of trainers and students about open learning. The ideas for interdisciplinary tasks and projects for computer science as well as for foreign languages based on the three principles: freedom of choice, cooperation or interaction between pupils, and budgeting time. These confirm one sentence by Maria Montessori: "The teacher is more a coach or facilitator than an instructor». Finally, according to COOL experiences, the integration ICT in language learning and teaching is seen more interesting and more motivating than lessons related only to one specific subject [10].

The researcher Körös-Mikis supports that young children is able to learn to read and write easily, free frustration, with the assistance of PCs, their mother tongue as well as a language different from their own. The acquirement of the written and the spoken language is achieved when a pedagogical environment is created, according to Montessori's Method. Thus, she proposes the appropriate software Fairy-Tale World, a picture-book, designed for small children learning Hungarian in kindergarten and junior grades. The program is operated by children with a few keys or a mouse selected the word picture by one of 14 familiar topics, with 20 words each. Children can print and color their drawings and write their stories and at the same time they learn several hundred foreign words at their leisure. [11].

The research focuses on games and educational applications running on touch-screen devices for children aged between 2 to 4 years old, using seven particular gestures: Tap, Drag /Slide, Free Rotate, Drag \& Drop, Pinch, Spread, Flick. One of the four selected apps on the iPad is Montessori Crosswords and this selection, based on reviews in 2012, is considered popular, fun and interest for young children. The experiment for the selection of gesture has proved a powerful relationship between age and the gestures used, as well as the number of components is crucial when designing app interface. In this way, the successful gestures for children aged two years are tap and drag/slide, while all seven gestures can be used by children aged four years and above. Furthermore, the experiment have demonstrated that children have difficulty with using gestures on crowded interface design such as in Montessori Crossword that's why it is necessary use the appropriate number of components per screen for children apps. [12].

\section{MATHEMATICS AND GEOMETRY}

Zuckerman et al., exhibit digital Montessori -inspired manipulatives prototypes (MiMs) flow and system blocks which are a set of building blocks, are playful tools and accessible to young children. They demonstrate their personal or classroom use as modeling and simulation tools and besides they are concerned by abstract domains facilitating a physical, interactive, multi sensory experience. Specifically, system blocks can perform system dynamics involving concepts such as accumulation, rates and feedback as for example water flow through a bathtub. Flow blocks can perform mathematical concepts such as probability and counting, and computer concepts such as looping. The components' system blocks are stocks, flows which are rates, variables, the valves of flows and probes. The components' flow blocks are paths, generators, rules and probes. The generator block has a button that send out the first light and probes are additional representations. Thus, small-group children ranging in age from 6-11 yearolds played with flow blocks, created sequences, shaped loops which are called by children "squares" or "circles" as well as used the probes to perform counting and probability measurements. The authors' ascertain: "All the children loved to plug the Rules blocks in and out of the Paths, and see the immediate change in the simulation" [3].

Moyer-Packenham et al., examine young children's interactions with virtual manipulative mathematics iPad apps. These are mobile devices with a touch screen which support the visualization of mathematics concepts. Children use three different virtual manipulatives as hundreds board, number line, and counting beads for the Skip Counting tasks, and as base-10 blocks, number line, and number cards for representations of place value. Two of the six virtual manipulative mathematics apps on the iPad are Montessori Numbers (Quantity: 100-999) and 100s Board. The selection of virtual manipulative is based on their influence of positive learning. According to the question posed by the research, "How do interactions with virtual manipulative iPad apps immediately impact young children's learning performance and efficiency?" the results show significant improvements in learning performance and efficiency on the Skip counting task, in contrast on the Place Value task. Finally, the use of touchscreen devices for mathematics learning is more new, therefore the authors find necessary further research [13].

Besides, Vankúš mentions that didactical game as effective method of mathematics' education and he inquires through history and especially through Hellenic philosophers (Plato, Aristotle) and continues in modern era. Through great psychologists and philosophers such as J. Dewey, L. S. Vygotsky, F. Schiller, M. Montessori used extensively educational games in school setting as activity proper for children at the age from 3 to 6 years. Also, according to his research, educational games enable development of language needed for working with mathematical concepts [14].

Falcão et al., designed a tangible interface aimed pupils at overcome learning difficulties, especially learning of fractions in elementary schools in Brazil. Tangible user interfaces (TUIs) embed computing power in physical 
objects and through technological innovations, contribute to the learning process using multiple senses, touching, seeing and hearing. The researchers focus on the concepts of fractions explored through the manipulation of areas in geometric figures and they made a tangible interface called Parts\&Bits. It is constructed by a board of approximately $30 \mathrm{~cm} \times 40 \mathrm{~cm}$ and straight and curve sticks which are build on wood or plastic with magnetic connections. The sticks can be used to form 2D geometric figures on top of the board and this detected the arrangement of figures, calculates the fraction by an embedded ARM microprocessor. Also, the board illuminates areas of same size with the same color, and use different colors for different sizes through Light Emitting Diodes (LEDs). The students using the tangible user interfaces can explore with freedom, reasoning and understanding about the concept of fraction and of "whole". [15].

Rick et al., have been based on Constructionism as a consequence on Montessori's prepared environment. Thus, they use DigiTile as a case study by emphasizing on tools and environments, and support learning through exploration and creation. DigiTile as new technology is a Diamond Touch multi-touch table (Rick and Rogers 2008) with a horizontal display groupware, by designing colorful mosaic tiles, representing fraction concepts. Concretely, two learners using touch input can drag pieces into work snaps and this enables them to demonstrate their understanding the mathematical concepts. According to the case study, the researchers present how children in pairs of 9 and 10 year olds collaborate using the shareable version of DigiTile and also its learning benefits on a field study [16].

\section{COMPUTER SCIENCE}

At the end of the last century, Resnick et al. has developed at MJT Media Lab a new generation of "digital manipulatives". They enables in children's learning to explore computing thinking in particular, "systems concepts», unlike arithmetic and geometric concepts are explored by traditional manipulatives which are wellestablished in the school settings. Namely, the researchers have created by adding computation to four traditional children's toys-blocks, beads, balls, and badges originated from great educators such as Johann Heinrich Pestalozzi, Friedrich Froebel, Maria Montessori and Jean Piaget. These tools, called Programmable Bricks and Beads, BitBall contain several types of processors, light emitting diode (led), towline display as Thinking Tags, so people can communicate and interact with one another [17].

Afterwards, Zuckerman and Resnick, basing on Montessori's materials, present the System Blocks, a new physical interactive system with a view to explore dynamic systems and understanding their complex behavior. These blocks are composed of the sender, the accumulator, the delay, the multiplier, the converter and midi and all for these have input ports and output cables. The resulted behavior is relation to consider the blocks arrangement [18].

Woolsey and Woolsey, posing the question: "What are the Montessori materials of the $21^{\text {st }}$ century?" support the importance of technologies in current era seeing that young people are attracted by digital media which encourage learning with their playfulness. They describe new image and sound digital technologies that have been ac- cented in school environments and are favorable to exploration and play. The Apple Multimedia Lab has created software prototype digital Montessori materials, specifically the Visual Almanac (1990) provided with collections of images and sounds, a composition workspace with tools for creating new sequences and activities. Furthermore, VizAbility was initially designed in 1995, with sets of exercises that enhance one's basic visual literacy, including sections on the skills of seeing, drawing, diagramming, and imagining. Finally, the New Media Thinking Project that was established in 2006, design prototypes providing youth with templates to organize their school reports and to expose them to reasonable graphic design [19].

Miglino et al., confirm how the RFID/NFC technology enhances learning and teaching and according to their presentation, related to digital and physical didactical materials. Indeed, the block magic project with RFID technologies uses the traditional Logical blocks and consists of a set of magic blocks, a magic board/tablet device and specific software for children between 2.5 and 7 years old: "The object of the project is to recover some traditional psycho-pedagogical, Montessori-inspired approaches.....exploring the well-known methods (Montessori) for an enhancement with the digital technologies" (www.blockmagic.eu). On this way, another application is so-called Walden PECS Communicator WPC which reinforces the communication for children for special needs and finally,Wandbot system is installed in Museums, Science Centers and mass events that creates interactive exhibits in a wide area of subjects [20].

The TangibleK robotics program for young children is a robotics construction kit associated with the sector of computer science and engineering. Bers outlines a robotic kit for children involving programming the behaviors of the constructed artifact and also construction in the physical world. Thus, young children are invited to build their own robotic projects such as cars, elevators and puppets, enabled to learn about motors, programming, sensors, mechanics, and the digital area. This deeper understanding of abstracts concepts while the children play with educator robotics kits to learn is based on the tradition learning manipulatives of Montessori [21].

\section{VARIOUS OBJECTS}

\section{A. Geography}

In Kenya, the study on the use of ICT in teaching of Geography proves that includes a current tool. This, on the one hand helps learners become active and on the other hand teachers using a variety of instructional techniques and resources achieve the desired aims. In progressive education and development this philosophy refers to sensory-education theory of Maria Montessori. According to the researchers, the types of ICT materials that are useful for the teaching of Geography involve: computers, internet, radios, televisions, cell phones, audio visual devices, scientific calculators, weather focus devices and magnetic compasses [22].

\section{B. Ecology}

In article [23] is reported that the International Environmental Education Programme (IEEP) under the auspices of United Nations of Education Scientific and Cultural 
Organisation (UNESCO) produced the first set of environmental education objectives for the purpose of:

Development of a world population that is aware of [...] the environment and its associated problem and which has the knowledge, skills, attitudes, motivations and commitment to work individually and collectively toward solutions of current problems and the prevention of new ones. (UNESCO 1975, 40)

However, educationists such as Jean-Jacques Rousseau, John Dewey and Maria Montessori have included issues relating to environment in schools.

Environmental education and new digital technologies as electronic whiteboards, computers, tablets and smartphones in school setting are newcomers which help to be addressed the modern environment issues, for example the climate changes. In this object the resources are: Google Earth, virtual field trip [VFT], virtual museum, EJunior, virtual ecological pond (VEP) and video podcasts, Environmental virtual field trip [EVFL].

\section{Pease and religious education}

Dangwal and Srivastava explain how peace education is significant for humanity and mankind, including in the sense related to peace the concepts such as internal peace and harmony with environment, religious, the absence of violent act and also democratic governance. The teaching and learning of peace become effective with the use of ICT as a tool so that it combats the culture of violence and war. Thus, communication technologies such as the Internet, promote education, intercultural dialogue as well as online communities Google+, facebook, Twitter, Skype, etc., share information, experiences, knowledge and overall these make efforts to create a peaceful situation, although these are threatened by cyber-bulling. The authors reported for the International Day of Peace, September 21, promoting peace education appreciate the significant contribution of Maria Montessori. [24]

Moreover, Guetta analyzing the meaning of peace education as one of the fundamental values in humankind's development, reports that according to scholars, Maria Montessori was the first instructor who has reflected on peace education. This is evidenced by her educational work and by her script "Education for a New World" [25].

"Those who want war prepare young people for war; but those, who want peace, have neglected young children and adolescents so that they are unable to organize them for peace." MARIA MONTESSORI [24]

\section{History}

Raessens describes a mobile city game, called Frequency 1550 in which small groups of secondary-school pupils aged 12 to 14 playfully acquire specific historical knowledge about the city of Amsterdam. The city changes into a medieval playing-field with the help of the Internet, smart phones and GPS technology. With the collaboration of the Montessori Comprehensive School Amsterdam, the help of the Municipal Archives Amsterdam and the use of smart phones, GPS-technology and the Internet, the pupils, using a combination of a game and a story, create and develop their communication and collaboration skills. Moreover, through presentation and reflection with team members learn and appreciate the city and its history. He, also, describes existing plans for a Dutch National Historical Museum [26].

\section{ARtistic ANd Music EdUCATION}

According to a recent report of the joint Informatics Europe \& ACM Europe Working Group on Informatics Education (IE \& ACM, 2013), is an innovation for efficient teaching - learning processes wherefore algorithms learning are combined with sensory experience. Specifically, they concentrate on how dance can be involved in informatics education (sorting algorithms) and this is the particularity of the project. This artistic and technological involvement technological promotes intercultural computer science education. For researchers and teachers the terms multi -media and multi - sensory are entered about one hundred year ago by the pioneer Maria Montessori who signaled the digital era and confirmed that: "the extraordinary capacity of our brain to capture and process information from [all of] our senses" (Staley, 2006) [27].

The natural and immediate interaction for music practice in education and the direct contact with physical objects through their manipulation according to Montessori's scientific pedagogy is presented by standard and tactile interfaces. In this paper is showed both the IEEE 1599, an XML-based international standard for music description and a meta-instrument case study is showed as innovation idea. Namely, the IEEE 1599 standard as a descriptive format for music support multiple media encodings and synchronization and the Metapiano as a simple interface through which the musician can produce music [28].

Another educational mobile application 3DU Blocks library has been created by manipulating physical objectstoy blocks with the features by mobile devices. Garaizar et al., explain the use of this tool based on the principles of Montessori education that is "Independence, freedom and respect for the natural psychological development of the children" and also on the Montessori's areas: sensory, math, language and daily life. In sensory area, 3DU Blocks Music is applied and is available on the Apple App Store for devices running iOS. Moreover, tridimensional materials support and improve proper growing skills in each area [29].

Goh et al., describe the i-Cubes as cube-shaped digital manipulatives, employed in the design of two applications: MusiCube Arranger (MCA) for music composition and Spelling Cube for learning spelling. As Montessori's 'pink tower' have demonstrated the educational potential this way the tangible user interface, MusiCube Arranger allow children to explore and enjoy the creation of musical sequences and learn musical concepts. This is achieved by a system setup of the seven cubes and also a host PC which assumes a background role. The five Music element cubes (ME) and the Mode Selector (MS), with a combination of side by-side and vertical arrangements and another one the Instrument Selector (IS) include an embedded processor, sensors (orientation, motion and proximity) and outputs (colored lights and audio).Using the IS cube un instrument group is selected by the user and one starts by creating the rhythmic sequence. The another application the Spelling Cube (SC) engage preschool children in learning how to spell short 3-6 letter English words ,respectively with blocks, lights ,sound and computer screen. [30].

\section{CONCLUSIONS}

The purpose of this paper is to confirm that not only the Montessori Method is not outdated, but today's Infor- 
mation and Communication Technologies recall it. In fact, many educators and scientists around the word prove the existing relationship with children's brain development and as a result their intellectual growth and acquisition of knowledge based on Montessori's education of the senses. Furthermore, Montessori's materials are extending from traditional-physical to digital and technological tools and their enhancement which focus on capabilities and skills which among others include writing, reading, counting, foreign language learning and mathematics and musical concepts. New technologies are repeating Montessori's philosophy for the children's ecological, historical and peaceful instruction. In fact, the expanding Information and Communication Technologies (ICTs), computers, internet, audio visual devices ,radios, televisions, scientific calculators, as well as online communities such as Google + , facebook, Twitter and all similar technologies have developed so to prepare environments in schools and are gradually integrated in the learning process. Most of these technologies reproduce Montessori's materials and children using touch-screen devices such as games nowadays divert and in a parallel manner have a strong effect on education outside the wall of the classroom. To sum up, the creativity and the innovation of an educationist in the 1900 in Italy has revived and enriched contemporary education through the use of ICTs.

\section{REFERENCES}

[1] Sabitzer, Barbara. "Neurodidactics-A New Stimulus in ICT and Computer Science Education." INTED (2011): 5881-5889.

[2] Shams, Ladan, and Aaron R. Seitz. "Benefits of multisensory learning." Trends in cognitive sciences 12.11 (2008): 411-417. http://dx.doi.org/10.1016/j.tics.2008.07.006

[3] Zuckerman, Oren, Saeed Arida, and Mitchel Resnick. "Extending tangible interfaces for education: digital montessori-inspired manipulatives." Proceedings of the SIGCHI conference on Human factors in computing systems. ACM, 2005. http://dx.doi.org/10.1145/1054972.1055093

[4] Zuckerman, Oren, et al. "The state of tangible interfaces: projects, studies, and open issues." CHI'06 Extended Abstracts on Human Factors in Computing Systems. ACM, 2006. http://dx.doi.org/10.1145/1125451.1125468

[5] Zuckerman, Oren. System blocks: learning about systems concepts through hands-on modeling and simulation. Diss. Massachusetts Institute of Technology, 2004.

[6] Klemmer, Scott R., Björn Hartmann, and Leila Takayama. "How bodies matter: five themes for interaction design." Proceedings of the 6th conference on Designing Interactive systems. ACM, 2006. http://dx.doi.org/10.1145/1142405.1142429

[7] Zuckerman, Oren. "Historical overview and classification of traditional and digital learning objects." Accessed (February, 2011) from (2006).

[8] Nunn, Pamela. "The Mind and the Hand: Implications of Recent Research on Montessori Theory and Practice." Honouring the Human Potential (1998).

[9] Di Blas, Nicoletta, and Paolo Paolini. "Digital Storytelling at School: Engagement and Educational Benefits." 2012 IEEE 12th International Conference on Advanced Learning Technologies. IEEE, 2012. http://dx.doi.org/10.1109/icalt.2012.91

[10] Sabitzer, B. "Informatics+ Foreign Language (s)= COOL (Cooperative Open Learning)." ICERI2011 Proceedings (2011): 13731381.

[11] Körös-Milds, Márta. "Learning languages in a creative way: Young children using the computer in discovering the written word and the spoken language." Educational Media International 31.3 (1994): 193-196. http://dx.doi.org/10.1080/0952398940 $\underline{310310}$
[12] Aziz, Abdul, et al. "Selection of touch gestures for children's applications." Science and Information Conference (SAI), 2013. IEEE, 2013.

[13] Moyer-Packenham, Patricia S., et al. "The Effects of Different Virtual Manipulatives for Second Graders' Mathematics Learning in the Touch-Screen Environment."

[14] Vankúš, P. E. T. E. R. "History and present of didactical games as a method of mathematics' teaching." Acta Didactica Universitatis Comenianae-Mathematics 5 (2005): 53-68.

[15] Falcao, Taciana Pontual, Luciano Meira, and Alex Sandro Gomes. "Designing tangible interfaces for mathematics learning in elementary school." Proceedings of III Latin American conference on human-computer interaction. 2007.

[16] Rick, Jochen, et al. "Learning by doing with shareable interfaces." Children Youth and Environments 19.1 (2009): 320-341.

[17] Resnick, Mitchel, et al. "Digital manipulatives: new toys to think with." Proceedings of the SIGCHI conference on Human factors in computing systems. ACM Press/Addison-Wesley Publishing Co., 1998. http://dx.doi.org/10.1145/274644.274684

[18] Zuckerman, Oren, and Mitchel Resnick. "A physical interface for system dynamics simulation." CHI'03 extended abstracts on $\mathrm{Hu}$ man factors in computing systems. ACM, 2003.

[19] Woolsey, Kristina, and Matthew Woolsey. "Child's play." Theory Into Practice 47.2 (2008): 128-137. http://dx.doi.org/10.1080/ 00405840801992330

[20] Miglino, Orazio, et al. "Bridging Digital and Physical Educational Games Using RFID/NFC Technologies." Journal of e-Learning and Knowledge Society 10.3 (2014).

[21] Bers, Marina U. "The TangibleK Robotics Program: Applied Computational Thinking for Young Children." Early Childhood Research \& Practice 12.2 (2010): n2.

[22] Nato, Luke Wakhungu, and Omoro Benjamin. "Types of ICT Materials available for Teaching of Geography in Secondary Schools in Rongo District."

[23] Fauville, Geraldine, Annika Lantz-Andersson, and Roger Säljö. "ICT tools in environmental education: reviewing two newcomers to schools." Environmental Education Research 20.2 (2014): 248283. http://dx.doi.org/10.1080/13504622.2013.775220

[24] Dangwal, Kiran Lata, and Ms Shipra Srivastava. "Fostering Peace Education through ICT."

[25] Guetta, Silvia. "From peace education to culture of peace: contexts and issues." Studi sulla formazione 16.1 (2013): 167-179.

[26] Raessens, Joost. "Playing history: Reflections on mobile and location-based learning." Didactics of microlearning. Concepts, discourses, and examples (2007): 200-217.

[27] Tóth, László, Alpar Karoly Adorjani, and Zoltan KATAI. "MultiSensory Informatics Education." Informatics in Education-An International Journal Vol13_2 (2014): 225-240.

[28] Ludovico, Luca Andrea, Mario Malcangi, and Giuseppina Rita Mangione. "Enhancing Performance Music Games in Education through the IEEE 1599 Standard." American Journal of $\begin{array}{llcrcr}\text { Educational } & \text { Research } & 2.7 & \text { (2014): } & 486-492 .\end{array}$ http://dx.doi.org/10.12691/education-2-7-10

[29] Garaizar, Pablo, O. Peña, and Jon Ander Romero. "Montessori in the mobile era: building new learning experiences through tangible user interfaces." INTED\} 2013 Proceedings\} 6385 (2013): 123-123.

[30] Goh, Wooi Boon, et al. "The i-Cube: design considerations for block-based digital manipulatives and their applications." Proceedings of the Designing Interactive Systems Conference. ACM, 2012. http://dx.doi.org/10.1145/2317956.2318016

\section{AUTHORS}

Athanasios Drigas is a Research Director at IITN.C.S.R. Demokritos. He is the Coordinator of Telecoms Lab and founder of Net Media Lab since 1996. From 1990 to 1999 he was the Operational manager of the Greek Academic network. He has been the Coordinator of Several International Projects, in the fields of ICTs, and eservices (e-learning, e-psychology, e-government, einclusion, e-culture etc). He has published more than 270 
PAPER

MONTESSORI METHOD AND ICTS

articles, 7 books, 25 educational CD-ROMs and several patents. He has been a member of several International committees for the design and coordination of Network and ICT activities and of international conferences and journals. (e-mail: dr@iit.demokritos.gr).

Eugenia Gkeka is a foreign language teacher. She has collaborated with N.C.S.R. 'Demokritos', Institute of
Informatics and Telecommunications, Telecoms Lab - Net Media Lab since last year in various research projects regarding the use of Information and Communication Technologies and Special Education (E-mail: eugkeka@yahoo.gr).

Submitted 19 January 2016. Published as resubmitted by the authors 25 February 2016. 